\title{
Utilization of Flood Simulation Technique in Urban Flood Warning - A Case Study on Fuzhou*
}

\author{
Shuaijie Li**, Yingxia Xie \\ China Academy of Urban Planning \& Design, Beijing 100037, China \\ **E-Mail : lishuaijie2006@163.com
}

Xiaotao Cheng

China Institute of Water Resources and Hydropower Research, Beijing 100038, China

Zhifen Chen

China Academy of Urban Planning \& Design, Beijing 100037, China

Received 8 March 2015

Accepted 16 May 2015

\begin{abstract}
Vulnerability of urban receptors in flood prevention is rising during the rapid urbanization, and emergency response strategies were introduced to strengthen the capacity of urban flood prevention and flood disaster response. Emergency plan for flood control, which is considered as one of the most important emergency response strategies, was studied in this thesis, and flood simulation technique was applied in urban flood warning and emergency response to improve the practicability and operability of the Emergency plan. Referring to achievements of flood warning at home and abroad, a set of proposed flood warning standard that involves early flood warning standard and flood warning standard of inundated area was made and introduced to Fuzhou city in this study. Several calculation schemes, involving flood scenarios with high possibility or the most dangerous situations, were designed for the case study, and then the calculation schemes were simulated by using the numerical model, and study of flood warning and emergency response was carried out on the basis of flood risk analysis results; and proper flood risk mitigation and emergency disposal measures were designed in the emergency plan. Practical application has also proved that flood simulation technique can improve the efficiency of urban stormwater Emergency Management, and flood simulation technique is proved to be a useful measure of flood hazard loss reduction and disasters cost control.
\end{abstract}

Key words: flood warning; emergency response; flood risk analysis; flood simulation technique; Fuzhou City

\section{洪水模拟技术在城市防洪预警中的应用一以福州为例}

\author{
李帅杰 ${ }^{1}$, 谢映霞 ${ }^{1}$, 程晓陶 ${ }^{2}$, 陈志芬 ${ }^{1}$ \\ 1.中国城市规划设计研究院，北京 100037, 中国 \\ 2.中国水利水电科学研究院，北京 $100038 ， 中$ 国
}

摘要：在快速的城市化进程中，城市面对水灾的脆弱性日益显现，通过对城市防洪预警技术及应急响应措 施进行研究, 可有效提高城市预防与应对洪涝灾害的能力。研究将城市洪涝仿真技术应用于城市防洪预警 体系和应急响应体制建设之中，以求借助于精确的洪水风险分析手段提高城市防洪应急预案的适用性和可 操作性。结合国内外在城市防洪预警方面的研究成果，为福州市提出了全城戒备预警和城区积水空间洪水 预警的建议启动标准, 分别按照最可能与最不利原则制定福州市暴雨与外江洪水的组合方案, 应用福州市 雨洪仿真模型对各设定情景的洪水风险进行模拟计算, 根据模拟结果开展防洪预警和应急响应研究工作,

* 基金资助：国家自然科学基金重点项目（50739003); 城市地标径流污染控制欲内涝防治规划研究（2013ZX07304-001-7）; 国家科技支撑计划（2012BAJ15B01） 
并为各方案布置合理的防洪应急处置措施, 从而为福州市的城市防汛预警工作的改进提供了技术支持。实 践应用亦证明精确的预警技术可提升城市雨洪应急管理效率, 亦可减轻洪涝致灾损失和灾害治理成本。

关键词：防洪预警；应急响应；洪水风险分析；洪涝仿真技术

\section{1 引言}

在快速城市化的进程中，一方面城市建成区面 积迅速扩张, 城乡界限日趋模糊化; 另一方面现代 化城市对供水、供电、供气、交通、通讯等生命线 系统依赖越来越强, 同时城市空间立体化开发程度 不断增高, 都使城市面对突发性暴雨洪水的脆弱性 日趋显现。为了有效抑制城市化进程中不断加剧的 洪涝灾害风险, 国内外众多学者针对承灾体的脆弱 性和洪涝灾害的突发性与可预防性提出了防洪应急 管理策略 ${ }^{[1-4]}$, 其中城市防洪预警措施可在洪涝灾害 发生与发展过程中为管理部门和公众提供洪水风险 信息, 现已成为世界范围内城市开展防洪减灾工作 的重要非工程措施 ${ }^{[5-7]}$ 。随着计算机及数值计算技术 的进步, 用于开展城市洪涝演算的水力学模型已有 着很高的计算精度, 基于水力学原理的数值计算模 型可逐时段给出城市的实时淹没范围、淹没水深、 街道流速分布等信息, 使精细化的防洪预警成为现 实。

城市洪涝灾害系统变化会增大洪水风险的不确 定性, 为了寻求积极有效的应对策略, 国内外众多 的学者和管理机构已在防洪预警领域做了大量的研 究和实践工作，在防汛预警模式、预警指标体系以 及预警等级划分等方面已有很多的经验和方法可供 借鉴。自 20 世纪 60 年代开始, 英国便将建设天气 和洪水预报预警系统作为防洪减灾的重要措施, 英 国气象局的天气预警系统和环境署的洪水预警标识 及含义是当前国际间较有代表性的预警模式之一。 英国现行的气象灾害预警机制包括早期预警（Early Warning) 和临灾预警 (Flash Warning) ${ }^{[5]}$, 早期预 警通常由气象部门提前 5 天发布 (内部), 临灾预警 至少在致灾事件发生前 2 小时发布; 考虑到气象预 报的不确定性, 在实际发布预警时灾害事件发生的 概率被用作划分预警级别的指标。法国气象局设立
了专门的气象灾害预警机构, 负责每天更新发布全 国气象预警图，气象预警关注的灾种包括强风、暴 雨、洪灾、冰冻、雪崩、酷暑及寒流等。预警图上 分别以绿色、黄色、橙色或红色标识标注某一时段 内省级行政区的风险状况 ${ }^{[7]}$; 除发布全国气象预警 图之外, 法国还建立了 “国家水文气象和洪水预防 支援中心”，其主要负责分析处理全国 50 多个 “水 位预测局” 和法国气象局每半小时或一刻钟更新一 次的雨量预测数据, 并在全国范围内发布水灾预警 信息。水灾预警时也以 4 种不同的颜色标识不同的 水灾等级: 绿色代表正常情况, 黄色代表轻度水灾, 橙色代表重度水灾, 红色代表特大水灾。以 4 种预 警颜色标注的水灾危险性分布地图作为水灾警报的 重要形式会被公布在法国的各大报纸、电视台及网 络上，居民根据所居住地区的水灾危险性等级做好 相应的防灾准备。

按照《国家防汛抗旱应急预案》要求, 当前国 内大部分城市已针对台风、暴雨内涝、江河洪水等 制定了防洪应急预案, 预案明确要求各城市启动四 级预警机制。以我国北京市、上海市、广州市和福 州市为例, 4 个城市最新公布实施的防洪应急预案 均启用了四级预警机制, 预警级别由低到高依次为 一般 (IV级)、较重 (III级)、严重 (II 级)、特别严 重 (I 级), 分别采用蓝色、黄色、橙色、红色作为 标识颜色。

本文以我国福州市为例, 将洪涝仿真模拟技术 应用于城市防洪预警机制的研究当中。《福州市防洪 防台风应急预案》规定福州市需要进行预警的洪水 类型包括江河洪水 (主要指闽江洪水) 和城区内涝, 研究过程中首先要为这两种类型的洪水设定合理的 预警启动标准, 根据各级启动标准设计洪涝模拟方 案, 应用建立的福州市雨洪仿真模型对设计方案进 行模拟分析, 基于计算结果对各方案设计洪水情景 进行预警及响应研究。 


\section{2 城市防洪预警模式概述}

\section{1 国内外防洪预警模式对比}

国际上防洪预警研究起步较早的国家，其预警 技术当前已进入精细化研究和实时更新的发展阶段。 英国和法国均已在全国范围内布置了密集的水文气 象监测站网, 并实施了长效的水文气象监测机制, 实时更新覆盖全国的水文和气象信息, 为防洪预警 技术在时间和空间上的精细化发展提供了技术支撑。 与之相似, 在日本岐阜县的重点防灾城市, 现行的 洪水警报技术的空间识别尺度已可细化至 $1 \mathrm{~km}^{2}$ 的 单元, 这是日本积极发展覆盖全国的雷达测雨、洪 水预报、地理信息系统等技术的成果。因此, 要推 动城市防洪预警能力的提高, 稳定持续的基础设施 建设和积极的科研投入不可或缺。

我国城市常发的洪水类型包括江河洪水、山洪、 暴雨洪水、风暴潮及天文潮等, 这些洪水灾害的预 警发布均由各级防汛抗旱指挥部负责, 因此习惯上 将常发的洪水风险预警统称为防汛预警。我国城市 已陆续开始启用分级预警机制, 如北京市、上海市、 广州市、济南市、福州市等发布实施的防汛应急预 案中均已对四级防洪预警的指标选取和等级划分提 供了详细的参考标准。

\section{2 基于数值模拟的预警模式}

综合分析国内大部分城市的防洪应急预案, 其 中具有代表性预警指标可归纳为以下几类：（1）反 映暴雨洪水量级及可能致灾后果的指标, 如时段降 雨量和积水深度指标; (2) 反映江河洪水量级及由 江河洪水诱发的次生洪水灾害指标, 如洪水频率、 洪潮水位、水库水位、管涌发展程度和防洪工程 (如 堤防）出险程度等;（3）反映山洪灾害风险及其引 发的次生地质灾害指标, 如山洪易发区的暴雨强度、 泥石流易发区前期土壤含水量等，（4）反映洪水灾 害可能造成的影响和损失的指标，如经济损失、受 淹人口及死亡人数等。上述的预警指标有些可通过 监测获取, 如降雨量、江河水位等; 有些则是难以 量化的, 如管涌发展程度和堤防出险程度等, 对这
类指标实施有规律的监测工作亦不易进行；还有一 些指标只能在险情发生发展过程中，通过实时监测 或灾后调查的方式获取，如反映洪灾破坏程度的指 标。

预警指标难以获取或监测机制不够完善是限制 我国防洪预警向实时化和精细化方向发展主要障碍, 如我国大部分城市的水文气象监测站网布局不够密 集, 其中还有部分水文气象指标缺乏长效观测机制, 气象预报预警技术也相对落后于发达国家。面对国 内防洪预警工作的现状，专家提出必须通过扎实推 进基础工作来提高防洪预警能力建设，然而当前因 城市化加速、极端气象频发使国内城市面临着前所 未有的防洪压力，必须寻求替代性的防洪预警模式 来弥补因基础设施等硬件缺失造成的洪水风险管理 技术短板。近些年，随着计算机及数值计算技术的 进步, 用于开展城市洪涝演算的水力学模型已有着 很高的计算精度, 基于水力学原理的数值计算模型 可逐时段给出城市的实时淹没范围、淹没水深、街 道流速分布等信息，这些信息可作为防洪预警发布 和更新的指标依据，因此借助于水力学模拟手段实 施城市防洪预警是可行的。

\section{3 城市洪涝仿真模型}

本文运用福州市雨洪仿真模型 ${ }^{[8]}$, 模拟不同设 计情景的洪涝风险特征，为基于情景的城市防洪预 警提供淹没范围、淹没水深、街道流速分布等风险 特征信息。福州市雨洪仿真模型对城市的下垫面、 防洪工程、排涝系统进行概化处理，以城区河道、 管道及地表的水流运动为模拟对象，其中平面水流 采用二维非恒定流方程描述; 对宽度较小的河道、 街道中的水流采用一维非恒定流方程描述。

模型在计算过程中采用无结构不规则网格对研 究区域进行离散, 水深由连续方程对任一网格的显 示离散化形式求得:

$$
\mathrm{H}_{i}{ }^{T+2 \Delta t}=\mathrm{H}_{i}{ }^{T}+\frac{2 \Delta t}{A_{i}} \sum_{k=1}^{K} Q_{i k}{ }^{T+\Delta t} l_{i k}+2 \Delta t q_{\mathrm{i}}{ }^{T+\Delta t}
$$

式中: $A_{i}$ 为网格 $\mathrm{i}$ 的面积; $I_{i k}$ 为 $\mathrm{i}$ 网格的第 $\mathrm{k}$ 条通道 
的长度; $Q_{i k}$ 为 $\mathrm{i}$ 网格的第 $\mathrm{k}$ 条通道上的单宽流量; $H_{\mathrm{i}}$ 为 $\mathrm{i}$ 网格的水深; $\Delta t$ 为时间步长; $q_{i}$ 为 $\mathrm{i}$ 网格的源 汇项; $T$ 为计算时刻。

河道型和陆面型通道上的流量采用简化的二维 非恒定流动量方程的离散格式计算, 忽略了动量方 程中的对流项, 保留方程中的局地惯性项、重力项 和阻力项, 离散形式如下:

$$
\mathrm{Q}_{j}{ }^{T+\Delta t}=\mathrm{Q}_{j}{ }^{T-\Delta t}-2 \mathrm{~g} H_{j} \Delta t \frac{\left(Z_{j 2}{ }^{T}-Z_{j 1}{ }^{T}\right)}{D L_{j}}-2 g \Delta t \frac{n^{2} \mathbf{Q}_{j}{ }^{T+\Delta t}\left|\mathbf{Q}_{j}{ }^{T-\Delta t}\right|}{H_{j}{ }^{7 / 3}}
$$

式中: $Z_{j 2}, Z_{j 1}$ 为 $\mathrm{j}$ 通道两侧单元的水位; $D L_{j}$ 为 $\mathrm{j}$ 通 道两侧单元形心到 $\mathrm{j}$ 通道中点的距离之和; $\mathrm{n}$ 为粮率; $\Delta t$ 为时间步长; $H_{j}$ 为通道 $\mathrm{j}$ 上的平均水深; $\mathrm{g}$ 为重力 加速度; $Q_{j}$ 为通道 $\mathrm{j}$ 上的单宽流量; $\mathrm{T}$ 为计算时刻。

市区内宽度较小的河道和街道设计为特殊性通 道, 通道内水流既沿着通道方向流动, 同时还与通 道两侧网格进行交换。沿通道方向的水流按一维明 渠非恒定流计算, 特殊通道与网格间的流量采用堰 流公式计算。特殊型通道上的水位和流量计算以特 殊节点为计算单元, 特殊节点由通道交点及其连接 的所有特殊通道 (取一半长度) 组成, 通道的宽度、 底高程均根据实际的河流或街道断面设计, 连续性 方程的离散格式如式 (3)。

$$
\mathrm{H}_{\mathrm{di}}^{T+2 \Delta t}=\mathrm{H}_{d i}{ }^{T}+\frac{2 \Delta t}{A_{d i}}\left(\sum_{k=1}^{N} Q_{i k}^{T+\Delta t} l_{i k}+\sum_{j=1}^{2 N} Q_{i j}^{T+\Delta l_{i j}}\right)+2 \Delta t q_{\mathrm{dit}}^{T+\Delta t}
$$

式中: $A_{d i}$ 为计算单元 $\mathrm{i}$ 的面积; $\sum_{k=1}^{N} Q_{i k}{ }^{T+\Delta t} t_{i k}$ 为计算时 段内沿通道方向流入和流出计算单元 $\mathrm{i}$ 的水量之和, 流入计算单元 $Q_{i k}$ 为正, 流出计算单元 $Q_{i k}$ 为负; $\sum_{j=1}^{2 N} Q_{i j}{ }^{T+\Delta t} l_{i j}$ 为计算时段内计算单元 $\mathrm{i}$ 与两侧网格间交 换水量之和, 流入计算单元 $Q_{i j}$ 为正, 流出计算单元 $Q_{i j}$ 为负; $q_{d i}$ 为计算单元 $\mathrm{i}$ 的源汇项; $H_{d i}$ 为计算单元 $\mathrm{i}$ 上的水深; $\Delta t$ 为时间步长; $\mathrm{T}$ 为计算时刻。

关于福州市雨洪仿真模型的建立、调试、验证、 误差原因分析等, 见参考文献[8]。

\section{4 防洪预警启动标准}

国内北京市在其公布实施的防汛应急预案中为 城区积水预警等级划分提供了参考标准; 国外 Price ${ }^{[9]}$ 在圣马丁岛洪水灾害管理研究中根据水深和 流速指标将城市的洪水风险作划分为 5 级，各级风 险的水深和流速阈值是基于城市交通、居民生活生 命和建筑等的承灾能力划定。所选国内外研究区的 洪水等级划分标准如表 1 所示。

\begin{tabular}{|c|c|c|c|c|c|c|}
\hline \multirow[b]{2}{*}{ 北京 } & 预警等级 & IV级（蓝色预警） & III级（黄色预警） & II 级（橙色预警） & I 级（红色预警） & - \\
\hline & 水深 $/ \mathrm{m}$ & $\begin{array}{l}\text { 道路: } 0 \sim 0.2 \\
\text { 立交桥: } 0 \sim 0.3 \\
\end{array}$ & $\begin{array}{c}\text { 道路: } \quad 0.2 \sim 0.3 \\
\text { 立交桥: } \quad 0.3 \sim 0.5 \\
\end{array}$ & $\begin{array}{cc}\text { 道路: } & 0.3 \sim 0.5 \\
\text { 立交桥: } & 0.5 \sim 1.0 \\
\end{array}$ & $\begin{array}{l}\text { 道路: } 0.5 \sim 1.0 \\
\text { 立交桥: }>1.0 \\
\end{array}$ & - \\
\hline \multirow{5}{*}{$\begin{array}{c}\text { 圣马丁 } \\
\text { 岛 }\end{array}$} & 风险等级 & 低 & 中等 & 高 & 很高 & 极高 \\
\hline & 水深/m & $<0.4$ & $0.4 \sim 0.8$ & $0.8 \sim 1.8$ & $1.8 \sim 2$ & $>2.0$ \\
\hline & 流速/(m/s) & $<0.5$ & $0.5 \sim 2.0$ & $2.0 \sim 3.0$ & $3.0 \sim 4.0$ & $>4.0$ \\
\hline & 流速*水深 & $<0.2$ & $0.2 \sim 0.5$ & $0.5 \sim 1.5$ & $1.5 \sim 2.5$ & $>2.5$ \\
\hline & 安全对象 & 居民和小型汽车出行 & $\begin{array}{c}\text { 重型交通工具和成年人 } \\
\text { 涉水行进 }\end{array}$ & 轻型建筑物 & 重型建筑物 & - \\
\hline
\end{tabular}

表 1 所选国内外城市洪涝等级划分标准

参考国内外的洪水风险分级研究成果, 并结合 《福州市防洪防台风应急预案》提供的防洪应急和 内涝灾害应急启动标准, 本文针对 24h 降雨量、洪
水重现期、淹没特征等指标为福州市提出建议性的 全城预警启动标准（见表 2) 和城区空间上的洪水 风险预警启动标准 (见表 3 )。 
表 2 福州市全城预警建议启动标准

\begin{tabular}{|c|c|c|}
\hline 预警级别 & 城区 & 道路 \\
\hline $\begin{array}{l}\text { IV级（蓝色预 } \\
\text { 警） }\end{array}$ & $\begin{array}{l}\text { (1)预报未来 } 24 \mathrm{~h} \text { 降雨量将达 } 80 \mathrm{~mm} \text { 以上或已经达到 } 80 \mathrm{~mm} \text { 且降雨可能持续; } \\
\text { (2)城区可能会有 }<5 \% \text { 的范围积水, 且积水深超过 } 0.2 \mathrm{~m} \text {, 累计淹没历时超过 } 3 \mathrm{~h} \mathrm{;} \\
\text { (3)闽江下游洪水已超过警戒水位但小于 } 10 \text { 年一遇水平, 且水位可能继续上涨。 }\end{array}$ & $\begin{array}{l}\text { 城区可能会有 }<5 \% \text { 的道路 } \\
\text { 积水, 且积水深超过 } 0.3 \mathrm{~m}\end{array}$ \\
\hline $\begin{array}{l}\text { III级（黄色预 } \\
\text { 警） }\end{array}$ & $\begin{array}{l}\text { (1)预报未来 } 24 \mathrm{~h} \text { 降雨量将达 } 100 \mathrm{~mm} \text { 以上或已经达到 } 100 \mathrm{~mm} \text { 且降雨可能持续; } \\
\text { (2)城区可能会有 } 5 \%-10 \% \text { 的范围积水, 且积水深超过 } 0.2 \mathrm{~m} \text {, 累计淹没历时超过 } 3 \mathrm{~h} ; \\
\text { (3)闽江下游洪水将发生 } 10 \text { 年一遇以上、 } 20 \text { 年一遇以下洪水, 且水位可能继续上涨。 }\end{array}$ & $\begin{array}{l}\text { 城区可能会有 } 5 \%-10 \% \text { 的道 } \\
\text { 路积水, 且积水深超过 } 0.3 \mathrm{~m}\end{array}$ \\
\hline $\begin{array}{c}\text { II 级（橙色预 } \\
\text { 警） }\end{array}$ & $\begin{array}{l}\text { (1)预报未来 } 24 \mathrm{~h} \text { 降雨量将达 } 167 \mathrm{~mm} \text { （10 年一遇）以上或已经达到 } 167 \mathrm{~mm} \text { 且降雨可能持 } \\
\text { 续; } \\
\text { (2)城区可能会有 } 10 \%-20 \% \text { 的范围积水，且积水深超过 } 0.2 \mathrm{~m} \text {, 累计淹没历时超过 } 3 \mathrm{~h} \\
\text { (3)闽江下游洪水将发生 } 20 \text { 年一遇以上、 } 50 \text { 年一遇以下洪水, 且水位可能继续上涨。 }\end{array}$ & $\begin{array}{l}\text { 城区可能会有 } 10 \%-20 \% \text { 的 } \\
\text { 道路积水, 且积水深超过 } \\
0.3 \mathrm{~m}\end{array}$ \\
\hline $\begin{array}{l}\mathrm{I} \text { 级（红色预 } \\
\text { 警） }\end{array}$ & $\begin{array}{l}\text { (1)预报未来 } 24 \mathrm{~h} \text { 降雨量将达 } 200 \mathrm{~mm} \text { 以上或已经达到 } 200 \mathrm{~mm} \text { 且降雨可能持续; } \\
\text { (2)城区可能会有 } 20 \% \text { 以上的范围积水，且积水深超过 } 0.2 \mathrm{~m} \text {, 累计淹没历时超过 } 3 \mathrm{~h} \text {; } \\
\text { (3)闽江下游洪水将发生 } 50 \text { 年一遇以上洪水, 且水位可能继续上涨。 }\end{array}$ & $\begin{array}{l}\text { 城区可能会有 } 20 \% \text { 以上的道 } \\
\text { 路积水, 且积水深超过 } 0.3 \mathrm{~m}\end{array}$ \\
\hline
\end{tabular}

表 3 福州市城区积水空间洪水预警建议启动标准

( $H$ 为最大淹没水深, 单位为 $m$; $T$ 为淹没历时, 单位为 $h ; V$ 为流速, 单位为 $m / s 。$ )

\begin{tabular}{|c|c|c|c|}
\hline 预警级别 & 积水区 & 积水道路 & 备注 \\
\hline IV级（蓝色预警） & $0.2 \leqslant \mathrm{H}<0.3, \mathrm{~T} \leqslant 1$ 。 & $0.2 \leqslant \mathrm{H}<0.3, \mathrm{H}^{*} \mathrm{~V} \leqslant 0.2$ & 城市交通不便 \\
\hline III级（黄色预警） & $\begin{array}{l}\text { 当符合下列条件之一时可发布积水 } \\
\text { 空间黄色预警： } \\
0.2 \leqslant \mathrm{H}<0.3, \quad \mathrm{~T}>1 ; \\
0.3 \leqslant \mathrm{H}<0.5, \quad \mathrm{~T} \leqslant 1 \text { 。 }\end{array}$ & $\begin{array}{l}\text { 当符合下列条件之一时可发布道路 } \\
\text { 黄色预警: } \\
\text { (1) } 0.3 \leqslant \mathrm{H}<0.5, \quad \mathrm{H}^{*} \mathrm{~V} \leqslant 0.5 \text {; } \\
\text { (2) } 0.2 \leqslant \mathrm{H}<0.3, \quad \mathrm{H}^{*} \mathrm{~V}>0.2 \text { 。 }\end{array}$ & $\begin{array}{l}\text { 城市交通受到严重影 } \\
\text { 响 }\end{array}$ \\
\hline II 级（橙色预警） & $\begin{array}{l}\text { 当符合下列条件之一时可发布积水 } \\
\text { 空间橙色预警： } \\
0.3 \leqslant \mathrm{H}<0.5, \quad \mathrm{~T}>1 ; \\
0.5 \leqslant \mathrm{H}<1.0, \quad \mathrm{~T} \leqslant 1 \text { 。 }\end{array}$ & $\begin{array}{l}\text { 当符合下列条件之一时可发布道路 } \\
\text { 橙色预警: } \\
\text { (1) } 0.5 \leqslant H<1.0, \quad H^{*} V \leqslant 1.0 ; \\
\text { (2) } 0.3 \leqslant H<0.5, \quad H^{*} V>0.5 \text { 。 }\end{array}$ & $\begin{array}{l}\text { 城市交通、基础设施和 } \\
\text { 轻型建筑物受到威胁 }\end{array}$ \\
\hline I 级（红色预警） & $\begin{array}{l}\text { 当符合下列条件之一时可发布积水 } \\
\text { 空间红色预警： } \\
0.5 \leqslant H<1.0, T>1 ; \\
H \geqslant 1.0 \text { 。 }\end{array}$ & $\begin{array}{l}\text { 当符合下列条件之一时可发布道路 } \\
\text { 红色预警: } \\
\text { (1) } H \geqslant 1.0 ; \\
\text { (2) } 0.5 \leqslant H<1.0, \quad H^{*} V>1.0 \text { 。 }\end{array}$ & $\begin{array}{l}\text { 城市交通、基础设施和 } \\
\text { 各类建筑物均已受到 } \\
\text { 威胁 }\end{array}$ \\
\hline
\end{tabular}

\section{5 基于情景模拟的预警研究}

当前由暴雨洪水引发的内涝灾害已成为严重威 胁福州市城市安全的自然灾害之一, 与闽江洪水相 比, 城区内涝不仅更为频发而且影响范围也更广泛。 本文以福州市中心城区内涝作为示例洪水类型对福 州市城区进行预警响应分析。

\section{1 模拟方案设计}

洪水情景模拟方案的降雨量分别取为表 2 中四
级预警启动条件的临界降雨量值, 即 IV 级（蓝色） 预警降雨条件为 $80 \mathrm{~mm} / 24 \mathrm{~h} 、$ III级 (黄色) 预警降雨 条件为 $100 \mathrm{~mm} / 24 \mathrm{~h} 、 \mathrm{II}$ 级 (橙色) 预警降雨条件为 $167 \mathrm{~mm} / 24 \mathrm{~h} 、 \mathrm{I}$ 级 (红色) 预警降雨条件为 $200 \mathrm{~mm} / 24 \mathrm{~h}$; 闽江水位均为 1 年一遇水平。设计暴 雨雨型分布如图 1 所示。

\section{2 情景模拟方案的计算及预警}

经计算得到各设计方案下福州市城区及道路的 淹没范围、淹没历时、洪水流速等淹没特征信息， 

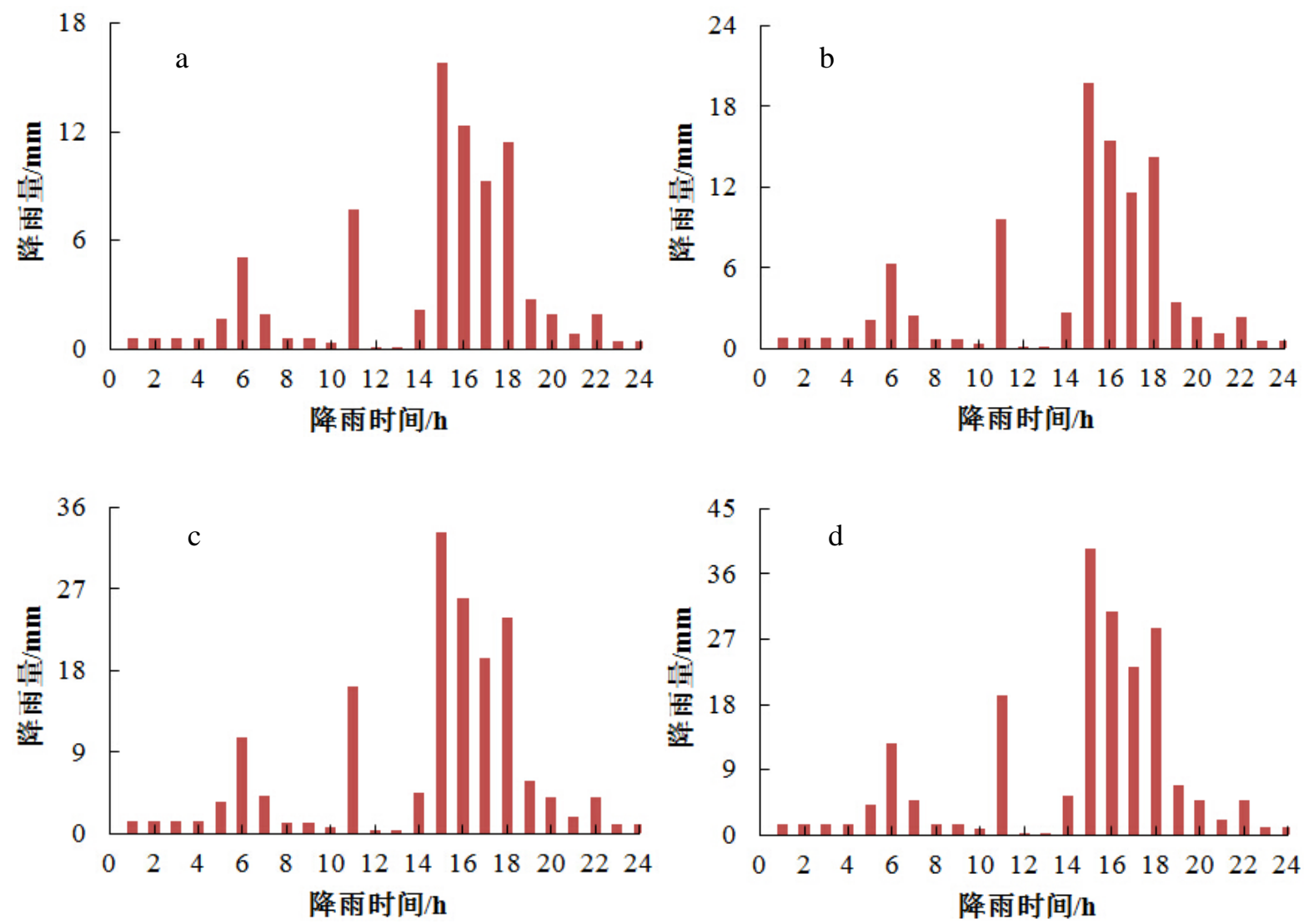

图 1 I -IV 级预警设计降雨雨型分布, a,b,c,d 分别代表IV, III, II, I 级预警设计降雨雨型分布

参照表 3 给出的积水区和积水道路上的洪水预警启 动标准, 对模拟的淹没特征信息进行预警等级划分, 并发布城区最大淹没水深分布图、城区和道路预警 图 (如图 2 6 所示)。

\section{3 响应分析}

基于上述计算分析及发布的预警结果可知，福 州市中心城区洪水高风险区主要分布于福新铁路线 以北的河道汇聚区域、铁路线以南的晋安河沿线区 域、光明港两侧低洼区域、磨洋河沿线低洼区域。 通过对各主要洪水风险区的洪涝成因和特性进行分 析, 为福州市洪水管理提出可行的预警响应对策。

（1）积水区预警响应

福州市中心城区铁路线以北的新店区地势四周 高中间低, 山溪河道汇集之后进入晋安河上游段, 晋安河和湖前河经铁路涵洞进入城区。受区域排水
能力及涵洞过水能力所限, 新店区靠近铁路线的低 洼区域特别容易积涝成灾, 琴亭人工湖建成之后, 区域就地的调蓄作用有效的缓解了新店区的防洪压 力; 同时区域治涝还可考虑 “高水高排” 的措施, 即通过建设排洪设施将新店区北部山地集雨区上形 成的径流水体引入闽江，不仅可以缓解低洼区的排 涝压力, 而且也会很大程度地减轻晋安河和湖前河 的行洪压力。

福州市城区排水系统以内河河道为主干泄洪通道, 若遇超标准降雨过程内河行洪压力较大, 河道沿线 低洼区域往往因排水受阻形成内涝。由城区预警结 果（图 4a）可以看出, 在全城启动III级以上洪水预 警的降雨条件下, 靠近晋安河的五四北路-五四路五一北路-五一中路沿线、六一北路-六一中路沿线 均会出现不同程度的积水内涝现象。特别在 II 级预 警和 I 级预警的降雨条件下，晋安河沿线低洼区域 


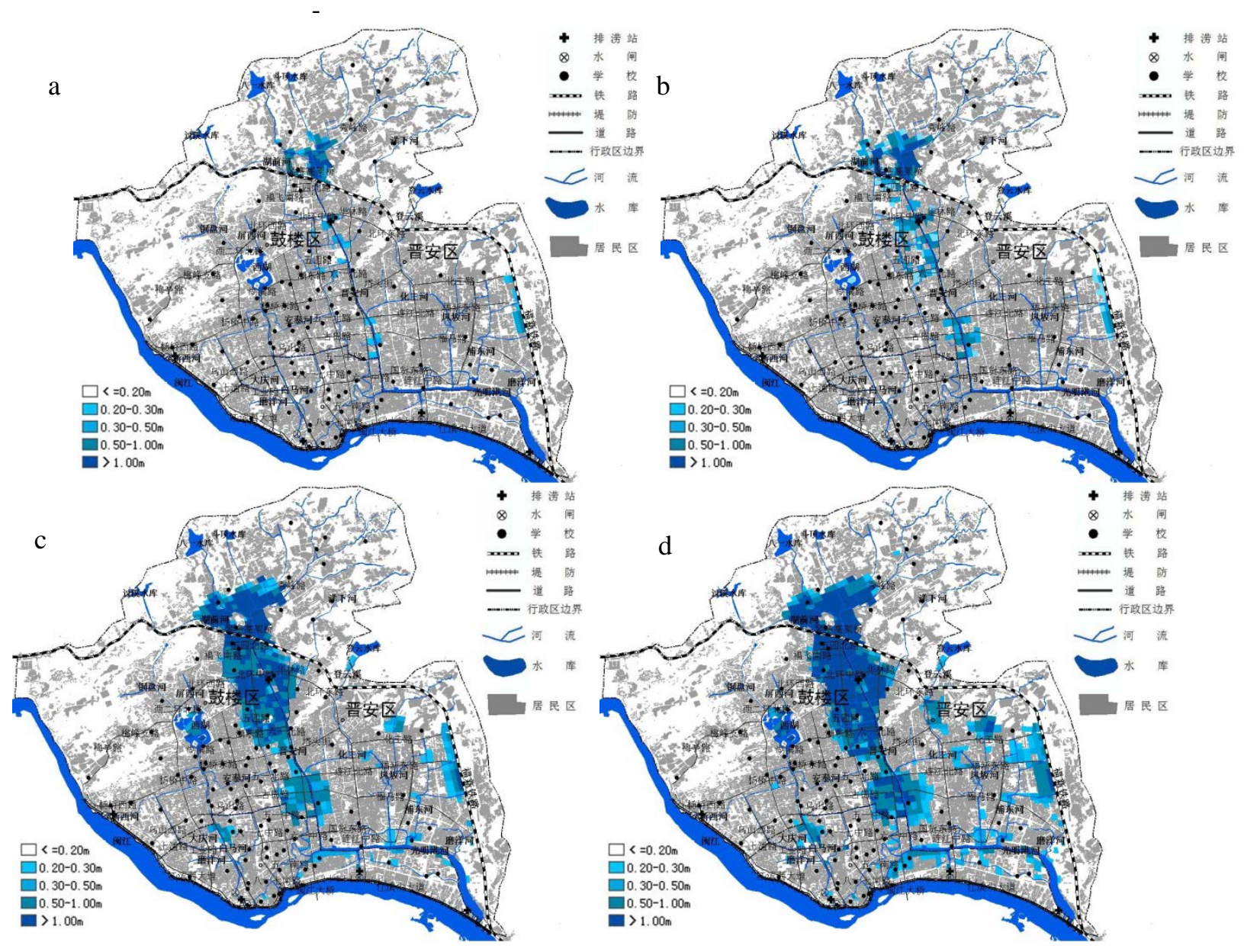

图 2 I - IV 级预警城区最大淹没水深分布图, a,b,c,d 分别代表IV, III, II, I 级预警城区最大淹没水深分布图
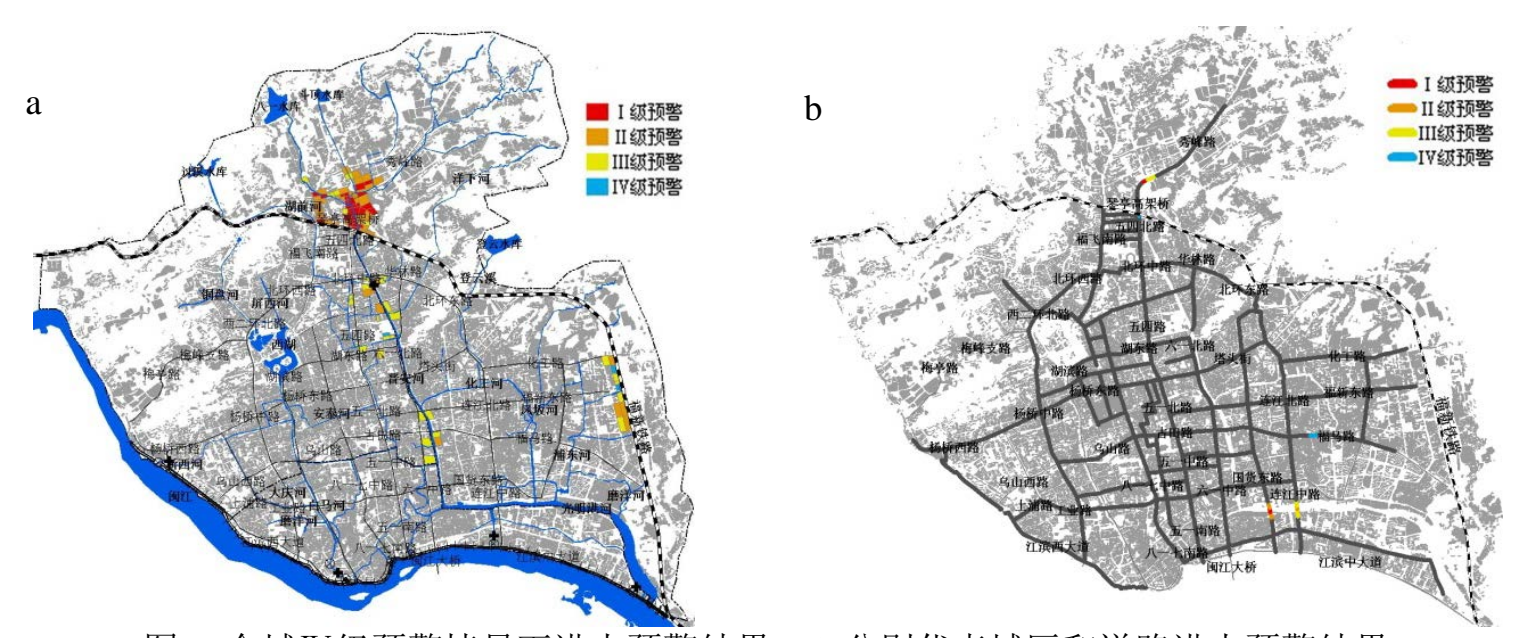

图 3 全城IV 级预警情景下洪水预警结果, a,b 分别代表城区和道路洪水预警结果 

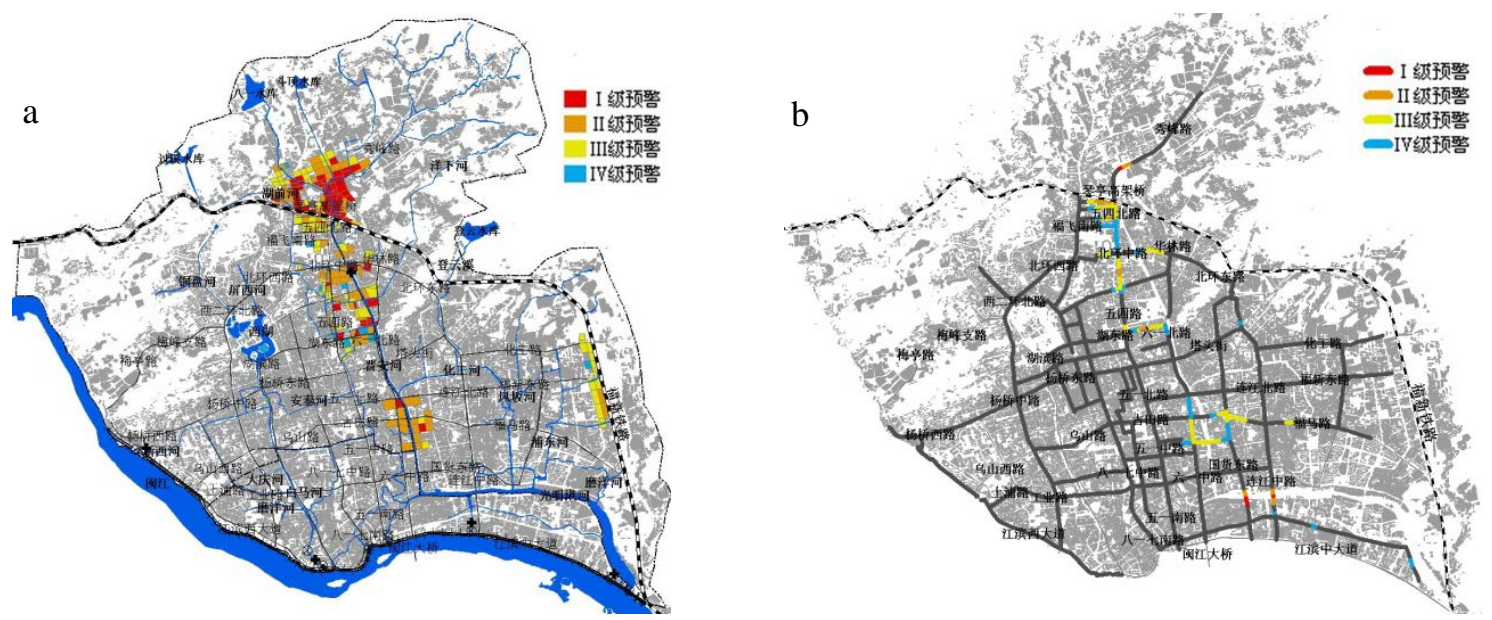

图 4 全城 III 级预警情景下洪水预警结果, a,b 分别代表城区和道路洪水预警结果
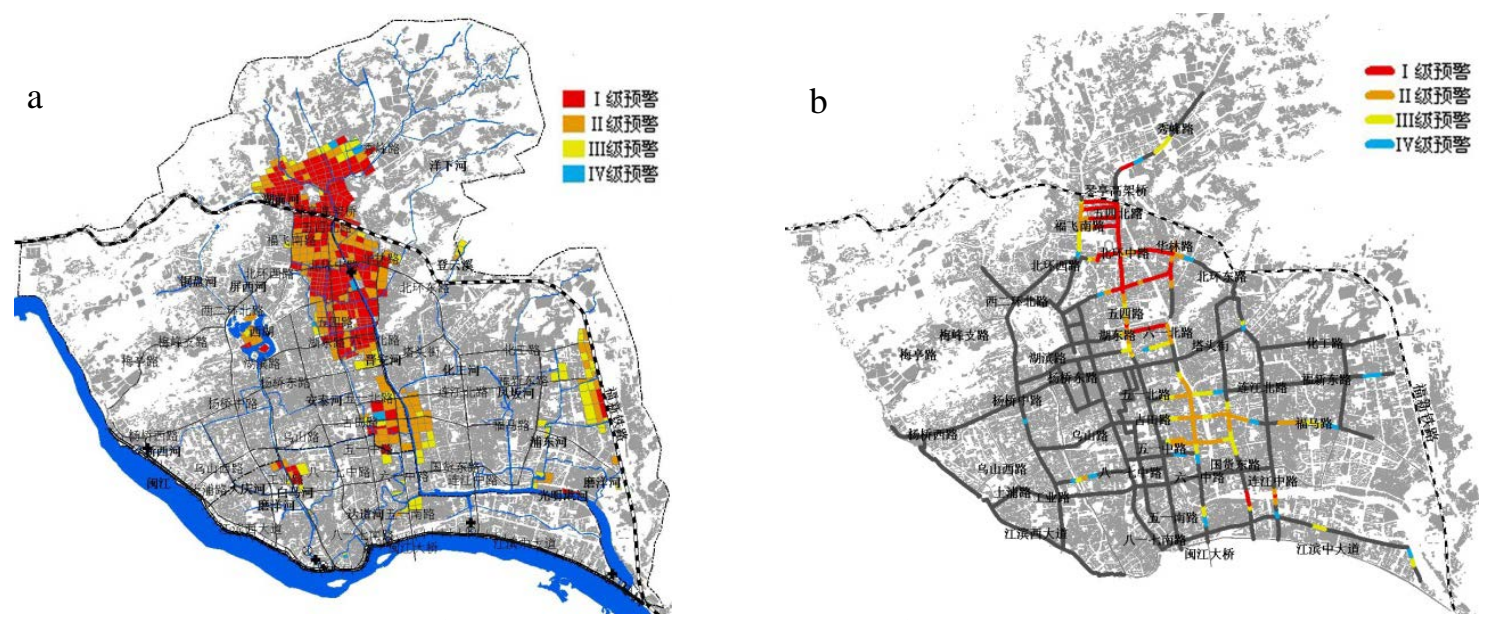

图 5 全城 II 级预警情景下洪水预警结果, a,b 分别代表城区和道路洪水预警结果
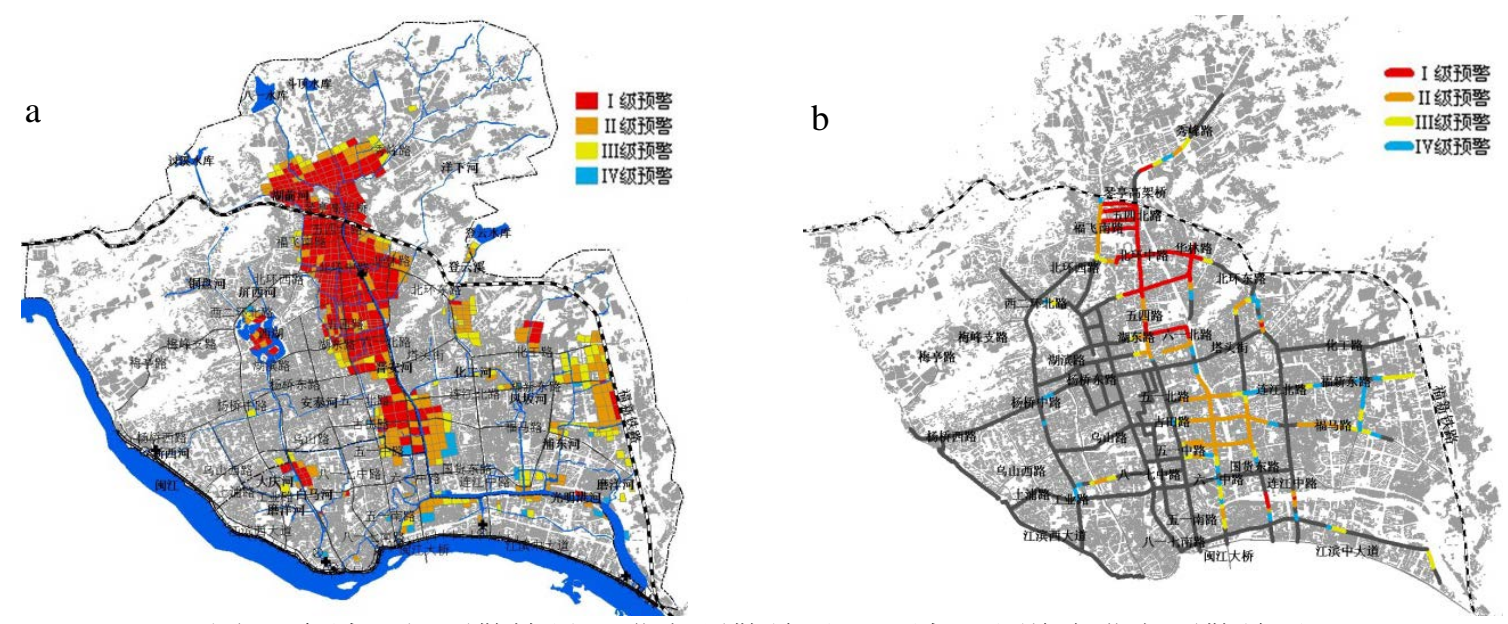

图 6 全城 I 级预警情景下洪水预警结果, a,b 城区和道路洪水预警结果

积水深可超过 $1 \mathrm{~m}$ （图 2c、d），行成大面积的红色 预警范围(图 6a)。为有效解决该区域的洪涝问题,
必须对城区的排水需求进行科学分析，编制合理的 排涝工程规划，加强城区基础排水设施建设，具体 
包括增大地下排水能力、内河河道治理、增大泵站 排水能力等。

（2）积水道路预警响应

在发生暴雨洪水期间, 顺街道行洪现象是造成 城市交通拥堵、抢险救灾受阻、居民自救与避难转 移困难等问题的主要原因。由城区道路四级洪水预 警图可以看出，城区易发生顺街行洪的路段包括秀 峰路、五四北路、五四路、华林路、北环中路、湖 东路、六一北路、福新路、福新中路、古田路、福 马路等。针对城区道路积涝问题, 可借助于洪水模 拟手段对不同降雨情景下城区道路的积水情况发 布预警信息，基于洪水预警信息管理部门可制定防 洪准备及抢险救灾措施。洪水预警信息可辅助交通 部门提前对可能出现积涝的路段进行交通管制, 如 在全城III级、II 级和 I 级道路预警方案中（图 4b, 图 5b, 图 6b), 发布黄色、橙色和红色预警的路段 积水深均已超过 $0.30 \mathrm{~m}$, 已可能对车辆的安全行驶 构成威胁, 管理部门应提前限制路段行车, 并通过 广播、电视、通讯等媒介将交通限制及改道等信息 告知市民; 洪水预警信息可辅助防洪部门提前对洪 水高风险路段开展防洪准备, 如全城 II 级和 I 级预 警方案中，城区的五四北路、五四路、华林路、福 新路、福马路等路段已形成了大范围积涝（图 5b, 图 6b)，橙色预警和红色预警路段的积水深超过 $0.5 \mathrm{~m}$ 且积水历时也均超过 $1 \mathrm{~h}$, 因此应当根据可能 出现的降雨与洪水情况, 在可能发生严重积涝的路 段设置活动洜车等临时排水设施, 及时将积水排向 行洪较为顺畅的西片区内河河道, 以确保居民避难 转移、应急部门抢险救灾等活动顺利进行。

\section{6 结论}

本文基于城市洪涝仿真技术开展防洪预警研 究工作, 得到以下结论:

(1)应用城市洪涝仿真模拟技术进行洪水预警 研究, 可为城市防洪与抢险救灾工作提供详细的洪 水风险信息, 可为城市防洪组织机构（包括防洪部 门、交通部门、民政部门、市政部门、物资储备部
门等）开展分区、分时、分类、分级的防洪应急管 理工作提供精确可靠的洪涝预警信息;

(2)洪水预警等级划分与防洪应急响应行动规 模紧密相关, 预警级别过低或过高可能会造成应急 响应行动的不足或过当，均会造成损失。基于模拟 技术的城市洪涝预警信息为城市防洪各部门间的 协同联动与快速反应提供了有效的技术支持, 不仅 有助于决策者制定合理的抢险调度方案、抢险救灾 措施和避难转移策略, 亦有助于不同部门各司其职, 保障应急行动的有序进行。

\section{参考文献}

1. J.Schanze et a. (ed. ), Flood Risk Management: Hazards, Vulnerability and Mitigation Measures. Earth and Environmental Sciences, 2006, 67:1-20.

2. Erich J Plate. Flood risk and flood management [J]. Journal of Hydrology, 2002,267:2-11.

3. Associated Programme on Flood Management. Urban Flood Risk Management - A tool for integrated flood management. 2008(3):28-33.

4. 澳大利亚 GHD 公司, 中国水利水电科学研究 院. 中国洪水管理战略研究 [M]. 郑州: 黄河水 利出版社, 2006.

GHD and IWHR. National Flood Management Strategy Study[M]. Zhengzhou: The Yellow River water conservancy press, 2006.

5.D.B.Stephenson, I.T.Jolliffe, C.A.T. Ferro. White Paper Review on the Verification of Warnings,http://www.metoffice.gov.uk/media/pdf/e /n/FRTR546.pdf, 4-22.

6. Michael Pitt. Learning Lessons from the 2007 Floods. http://archive.defra.gov.uk/.

7. Parker D J, Priest S J, Tapsell S. 2008. Modelling the Damage Reducing Effects of Flood Warnings, EU Floodsite Research Project Report, T10-07-12.

8. 李帅杰, 程晓陶, 郑敬伟等. 福州市雨洪模拟 [J]. 水利水电科技进展, 2011，31(5)：14-19. Li Shuaijie, Cheng Xiaotao, Zheng Jingwei, et al. Numerical simulation of rainstorm flood in Fuzhou City[J] . Advances in Science and Technology of Water Resources, 2011,31(5) : 14-19.

9. Price R, Vojinovic Z . Urban flood disaster management. Urban Water Journal, 2008,4(3), 259-276. 